\title{
Efficiency Analysis of Construction Automation Using 3D Geospatial Information
}

\author{
Joon Kyu Park ${ }^{1}$ and Keun Wang Lee ${ }^{2 *}$ \\ ${ }^{1}$ Department of Civil Engineering, Seoil University, 28, Yongmasan-ro 90-gil, Jungnang-gu, Seoul, Korea \\ ${ }^{2}$ Department of Multimedia Science, Chungwoon University, 113, Sukgol-ro, Nam-gu, Incheon, Korea
}

(Received October 15, 2021; accepted January 18, 2022)

Keywords: construction automation, geospatial information, laser scanner, point cloud, process management

The size of the global construction market is expected to increase to about $\$ 14$ trillion by 2025, with fierce competition expected in emerging markets. However, construction is the only industrial sector whose productivity has declined over the past 50 years. Over the past two decades, the world economy has grown by $2.8 \%$ and manufacturing productivity has grown by $3.6 \%$ annually, but labor productivity growth in the construction sector has averaged less than $1 \%$. Recently, construction companies have made various attempts to increase productivity, for example, by implementing 'smart construction' based on 3D data at all stages such as investigation, measurement, design, and construction. Many construction sites are increasing the utilization of building information modeling (BIM), laser scanners, unmanned aerial vehicles (UAVs), and automated construction equipment. However, studies on applying and analyzing 3D geospatial information in the construction process have been insufficient. In this study, an experiment on using 3D geospatial information technology in road construction was performed and analysis was conducted. The Global Navigation Satellite System (GNSS), static light detection and ranging (LiDAR), UAV LiDAR, and so forth were used to effectively build 3D geospatial information of the study area, and 3D designs were generated using the acquired data. The accuracy of data constructed through static LiDAR and UAV LiDAR was found to be within $0.025 \mathrm{~m}$ in the $X, Y$, and $Z$ directions. A 3D design reflecting the actual terrain was created, and various sensors were installed on construction equipment to conduct experiments on construction automation. The productivity of construction automation was evaluated by comparing the results of traditional and automated construction processes. In the future, construction automation using 3D geospatial information technology will contribute to improving productivity not only for roads, but also at many other construction sites such as tunnels.

\section{Introduction}

The Fourth Industrial Revolution (4IR) will lead to a marked improvement in productivity through convergence with information and communication technology (ICT) such as artificial

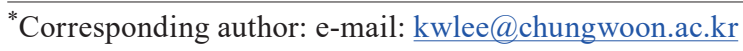

https://doi.org/10.18494/SAM3707 
intelligence technology, the Internet of Things and big data, and the intelligentization of products and services, resulting in innovative changes in the economy and society as a whole. ${ }^{(1)}$ In January 2016, the 4IR became known through the World Economic Forum, and in 2017, the Korean government announced its response strategy as the basic direction of its innovation policy. ${ }^{(2-4)}$ The 4IR response strategy of the Ministry of Land, Infrastructure and Transport (MOLIT) consists of smart national land creation, transportation service industry innovation, and public infrastructure safety innovation to improve the quality of people's lives through public service innovation and industrial competitiveness. ${ }^{(5-7)}$ In the meantime, the digital revolution has achieved much in the manufacturing and service industries. ${ }^{\left({ }^{8}-10\right)}$ For example, the process of designing and interpreting robots and 3D simulations through artificial intelligence technology have considerably improved the productivity of the automobile and consumer goods industries. $^{(11-12)}$ In contrast, the construction industry has changed little, while other industries have been undergoing such drastic innovations. ${ }^{(13)}$ However, construction has a lot of potential to improve productivity and efficiency through digitalization, innovative technology, and new construction technology. ${ }^{(11)}$ Augmented reality, unmanned aerial vehicles (UAVs), 3D laser scanning, building information modeling (BIM), robot construction, and more advanced building materials have begun to be applied. ${ }^{(7)}$ Through this, construction companies can improve productivity and improve quality and safety by effectively carrying out project management. Global construction-related spending is $\$ 10$ trillion, and the construction industry employs $7 \%$ of the world's workforce. ${ }^{(8)}$ The construction industry, which accounts for 25 to $40 \%$ of total global carbon emissions and is the largest consumer of raw materials, has a great impact on the economy, environment, and society, with all economic value creation processes linked to other industries. The size of the global construction market is expected to increase to about $\$ 14$ trillion by 2025, with fierce competition expected in emerging markets. Construction, however, is almost the only industrial sector whose productivity has declined over the past 50 years. Over the past two decades, the world economy has grown by $2.8 \%$ and manufacturing productivity has grown by $3.6 \%$ annually, but labor productivity growth in the construction sector has averaged less than $1 \% .{ }^{(9)}$

Recently, construction companies have made various attempts to increase productivity, for example, by implementing 'smart construction' based on 3D data at all stages such as investigation, measurement, design, and construction. ${ }^{(14)}$ Many construction sites are increasing the utilization of BIM, laser scanners, UAVs, and automated construction equipment. However, studies on applying and analyzing 3D geospatial information in the construction process have been insufficient. In this study, an experiment on using 3D geospatial information technology in road construction was performed and analysis was conducted. Figure 1 shows the study flow.

\section{Data Acquisition}

In this study, a site located in Gyeonggi-do, Korea, was selected as a study area to conduct experiments using 3D geospatial information technology for road construction. Figure 2 shows the study area. Surveying was needed for the 3D design of the study area, and data acquisition was performed in consideration of the difficulty in obtaining ground data due to vegetation. 


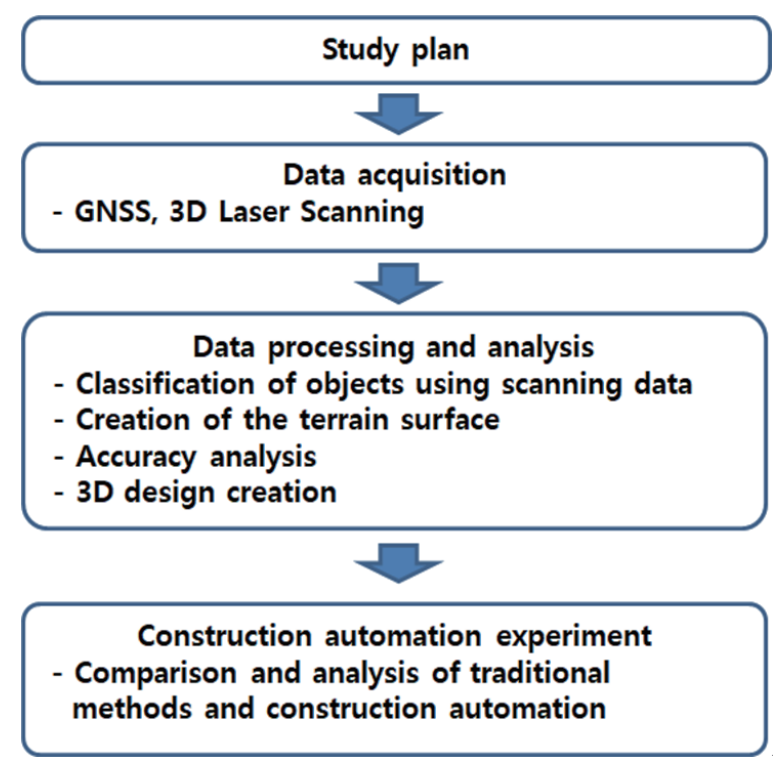

Fig. 1. Study flow.

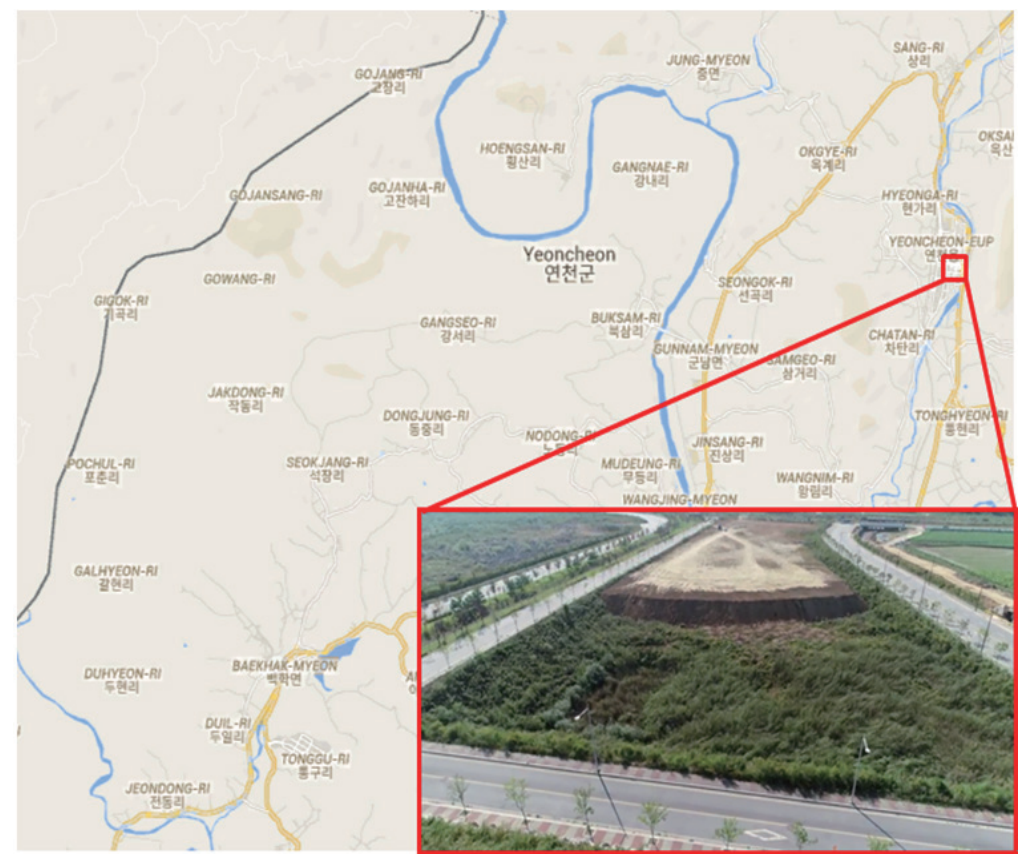

Fig. 2. (Color online) Study area.

GNSS and two types of scanner were used for surveying to obtain geospatial information for the area. GNSS was used for reference point surveying and data calibration, static light detection and ranging (LiDAR) was used for 3D laser scanning, and UAV LiDAR was used for data acquisition. The GNSS and LiDAR equipment used in this study are shown in Figs. 3-5. Data acquired by static LiDAR were used for georeferencing the data acquired by UAV LiDAR. Figure 6 shows static LiDAR data. 


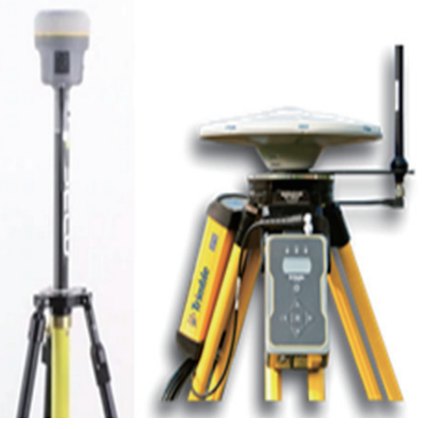

Fig. 3. (Color online) GNSS equipment. ${ }^{(15)}$

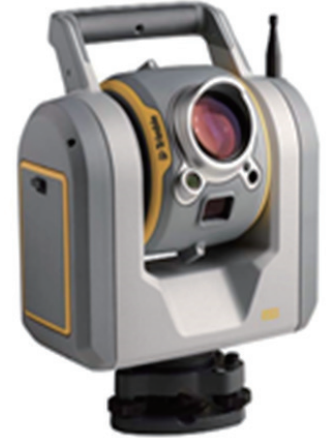

Fig. 4. (Color online) Static LiDAR equipment. ${ }^{(16)}$

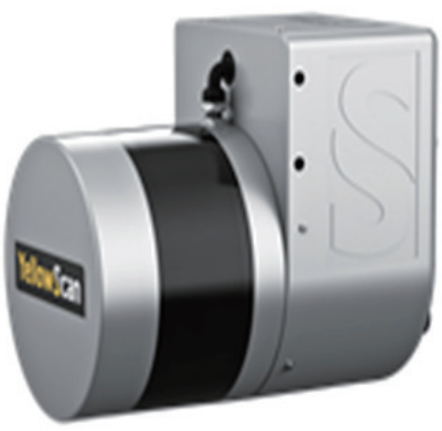

Fig. 5. (Color online) UAV LiDAR equipment. ${ }^{(17)}$

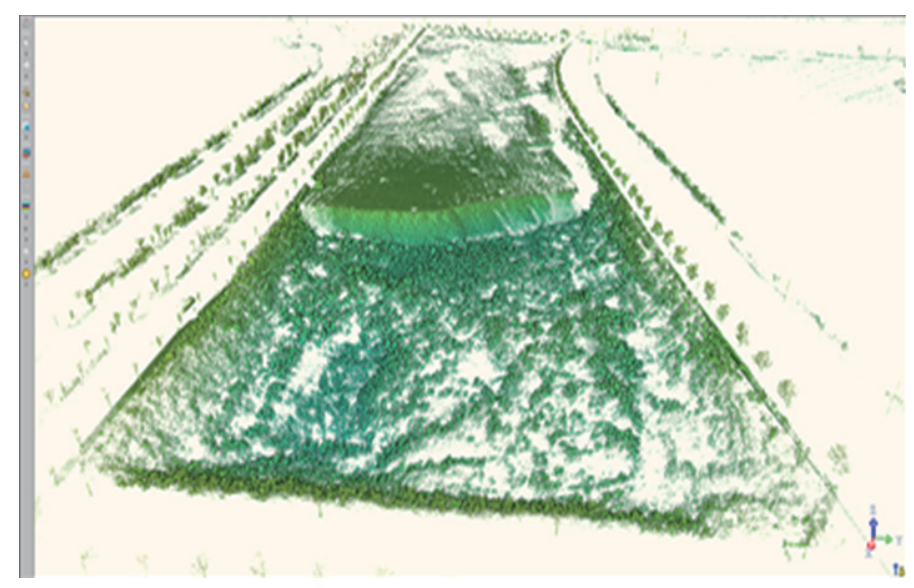

Fig. 6. (Color online) Static LiDAR data.

Static LiDAR data provide very accurate results because reference point data are used. However, as shown in Fig. 6, there are some areas with no data. Data acquisition must be performed at many points to overcome the lack of data, which was achieved using UAV LiDAR in this study. UAV LiDAR has a lower data accuracy than static LiDAR but has a high efficiency for data acquisition. To acquire data using UAV LiDAR, a mission plan for the study area was created and data acquisition was performed.

Data acquisition using UAV LiDAR took about 6 min, with a GNSS base station installed on the ground to improve accuracy, and data were logged at $1 \mathrm{~s}$ intervals. The coordinates of the base station were used for data processing. Finally, registration was performed using the static LiDAR data. Figure 7 shows the data acquired by UAV LiDAR.

\section{Data Processing and Analysis}

Ground data were generated using UAV LiDAR data for use in the design. The land and vegetation were classified using Trimble Business Center (TBC) software. Ground was classified 


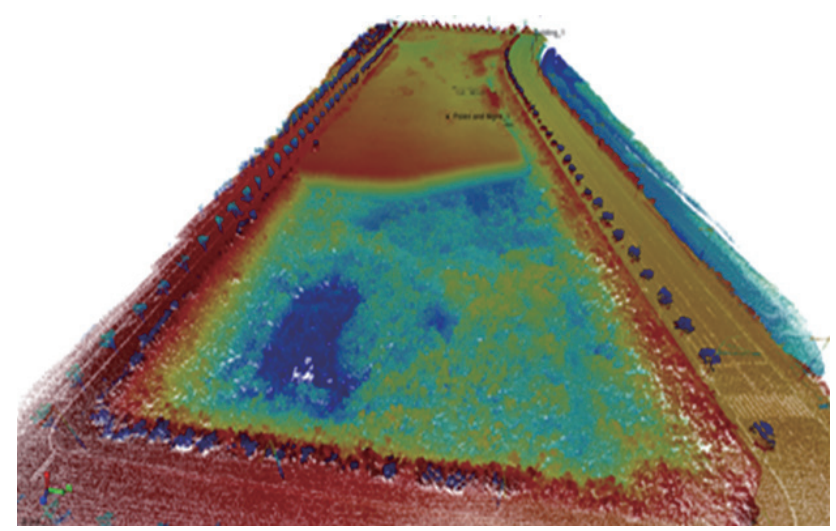

Fig. 7. (Color online) UAV LiDAR data.

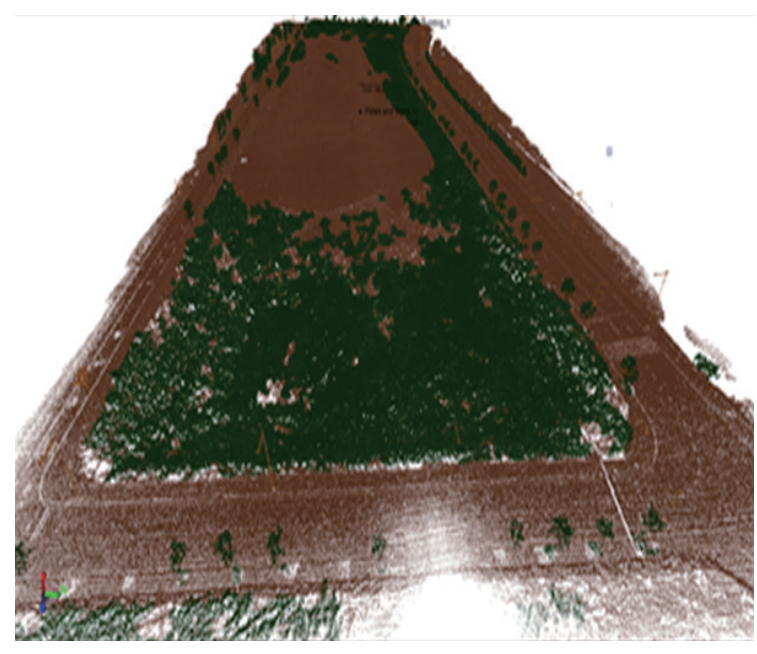

Fig. 8. (Color online) Classification result.

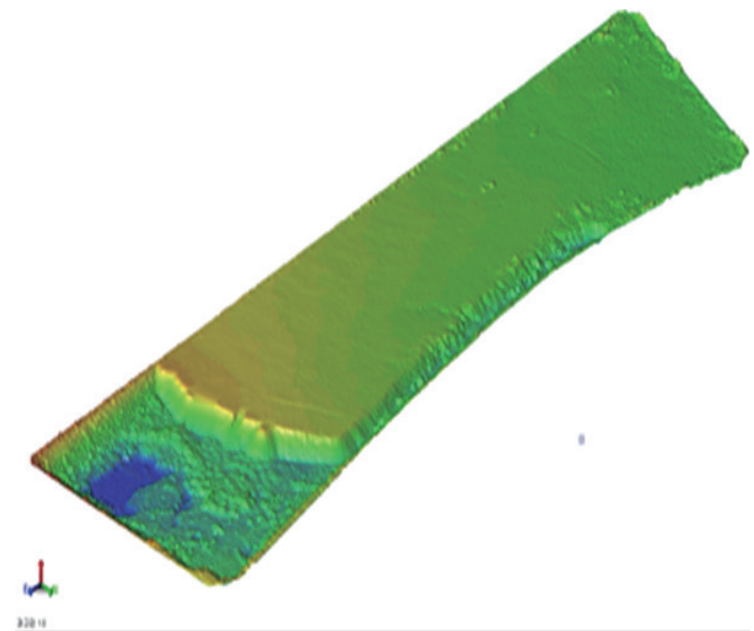

Fig. 9. (Color online) Mesh data for ground.

as brown and other (unnecessary) objects were classified as green. Through this classification, the data about the ground were generated, and mesh data were created to use the ground data for design. Since LiDAR data are point-cloud-type data, it is difficult to directly use them for design. Figure 8 shows the classification result and Fig. 9 shows mesh data for the ground.

3D design data must be applied to construction equipment in preparation for automated construction. For data preparation, the data obtained through static LiDAR and UAV LiDAR were registered and georeferenced, and accuracy was checked by comparison with GNSS survey results using 34 targets installed on the road around the study area. Table 1 shows the results of the accuracy check.

As shown in Table 1, the accuracy of data constructed through static LiDAR and UAV LiDAR was found to be within $0.025 \mathrm{~m}$ in the $X, Y$, and $Z$ directions. Since the study area is not large, the accuracy of LiDAR will need to be verified through additional research. 
Table 1

Results of accuracy check.

\begin{tabular}{lcccccc}
\hline No. & $X(\mathrm{~m})$ & $d(X)(\mathrm{m})$ & $Y(\mathrm{~m})$ & $d Y(\mathrm{~m})$ & $H(\mathrm{~m})$ & $d H(\mathrm{~m})$ \\
\hline ch1 & 613155.720 & 0.024 & 207135.920 & 0.021 & 65.450 & 0.021 \\
ch2 & 613129.710 & 0.021 & 207138.360 & 0.022 & 66.100 & 0.025 \\
ch3 & 613101.760 & 0.022 & 207140.960 & 0.025 & 66.750 & 0.021 \\
ch4 & 613078.820 & 0.022 & 207143.130 & 0.025 & 67.330 & 0.023 \\
ch5 & 613067.830 & 0.025 & 207144.140 & 0.021 & 67.600 & 0.024 \\
ch6 & 613064.130 & 0.026 & 207143.170 & 0.018 & 67.670 & 0.024 \\
ch7 & 613061.760 & 0.021 & 207139.010 & 0.017 & 67.660 & 0.025 \\
ch8 & 613059.880 & 0.018 & 207119.050 & 0.019 & 67.410 & 0.025 \\
ch9 & 613057.250 & 0.019 & 207091.070 & 0.024 & 67.040 & 0.025 \\
ch10 & 613054.520 & 0.022 & 207062.090 & 0.025 & 66.650 & 0.024 \\
ch11 & 613051.830 & 0.014 & 207033.150 & 0.019 & 66.220 & 0.020 \\
ch12 & 613049.590 & 0.020 & 207009.170 & 0.018 & 65.870 & 0.021 \\
ch13 & 613046.590 & 0.019 & 206977.200 & 0.017 & 65.440 & 0.022 \\
ch14 & 613043.490 & 0.021 & 206944.220 & 0.019 & 65.060 & 0.019 \\
ch15 & 613040.960 & 0.022 & 206917.230 & 0.018 & 64.680 & 0.018 \\
ch16 & 613038.980 & 0.021 & 206896.240 & 0.018 & 64.420 & 0.023 \\
ch17 & 613037.120 & 0.019 & 206876.270 & 0.019 & 64.130 & 0.025 \\
ch18 & 613035.430 & 0.017 & 206858.250 & 0.019 & 63.910 & 0.024 \\
ch19 & 613034.210 & 0.016 & 206845.260 & 0.020 & 63.740 & 0.023 \\
ch20 & 613031.790 & 0.021 & 206819.340 & 0.021 & 63.390 & 0.019 \\
cp1 & 613032.580 & 0.023 & 206835.170 & 0.022 & 63.470 & 0.022 \\
cp2 & 613036.660 & 0.024 & 206878.560 & 0.024 & 64.060 & 0.018 \\
cp3 & 613044.590 & 0.019 & 206963.200 & 0.019 & 65.140 & 0.024 \\
cp4 & 613053.220 & 0.018 & 207055.240 & 0.019 & 66.430 & 0.019 \\
cp5 & 613058.480 & 0.018 & 207111.340 & 0.019 & 67.180 & 0.023 \\
$\vdots$ & $:$ & $\vdots$ & $\vdots$ & $\vdots$ & $\vdots$ & $\vdots$ \\
\hline
\end{tabular}

Lines were entered to create a 3D design for the road to be built. For the linear road, a vertical line and a plane line were entered. Figure 10 shows the process of inputting road parameters. After inputting the alignment, a template representing the shape of the road with respect to the plane was entered every $20 \mathrm{~m}$ to represent the design values in three dimensions. Figure 11 shows some of the road templates.

Through input to the road parameter and template, a 3D design similar to the actual terrain of the target site was created. Figure 12 shows the completed 3D design, comprising data for two roads, one built by traditional road construction and the other built by automated construction.

Abnormalities were checked and the quantity of earthwork was calculated using the 3D design created through the study. Figure 13 shows a design check, and Fig. 14 shows the calculation of the amount of earthwork.

\section{Evaluating the Efficiency of Construction Automation}

To compare the traditional road construction method with the automated method, a road with a distance of $260 \mathrm{~m}$ was constructed by each method. An excavator, a dozer, a grader, and a compactor were the construction equipment used. To evaluate the automated road construction, 


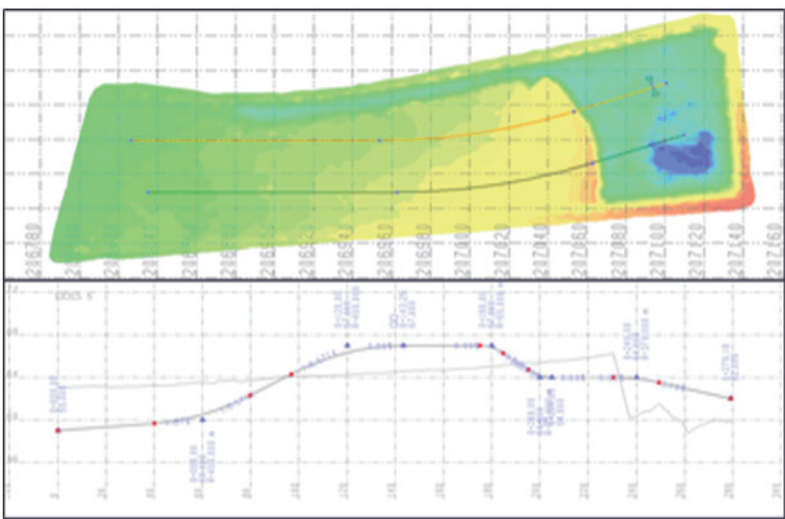

Fig. 10. (Color online) Process of inputting road parameters.

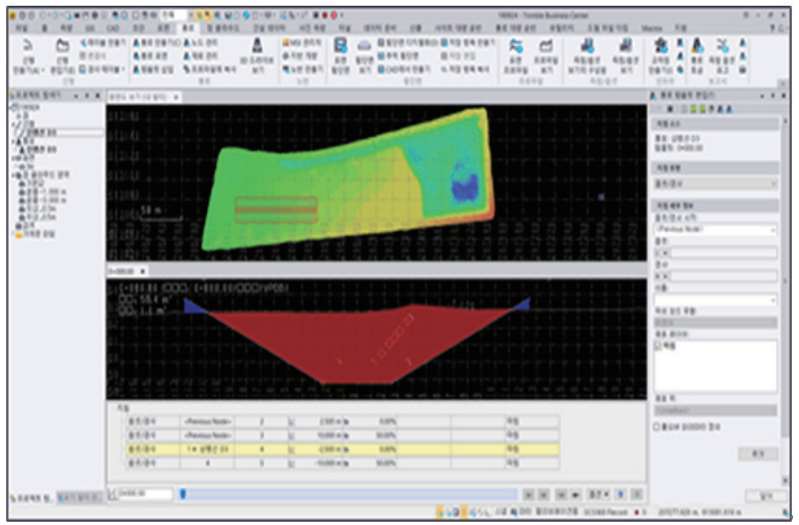

Fig. 11. (Color online) Road template.

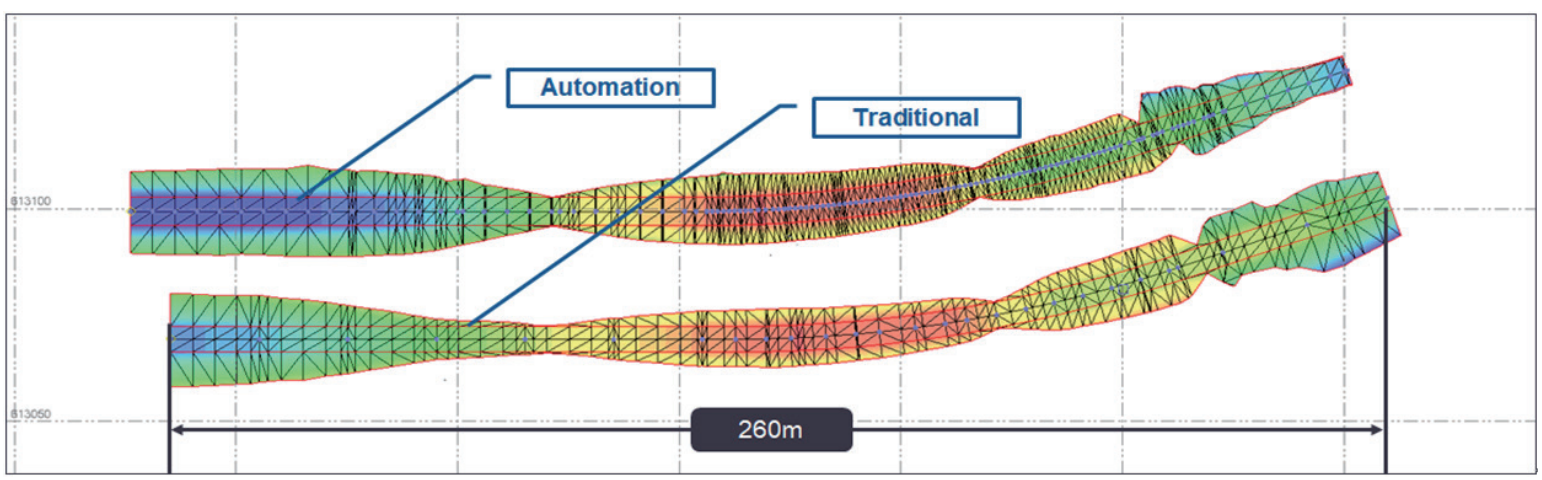

Fig. 12. (Color online) Completed 3D design.

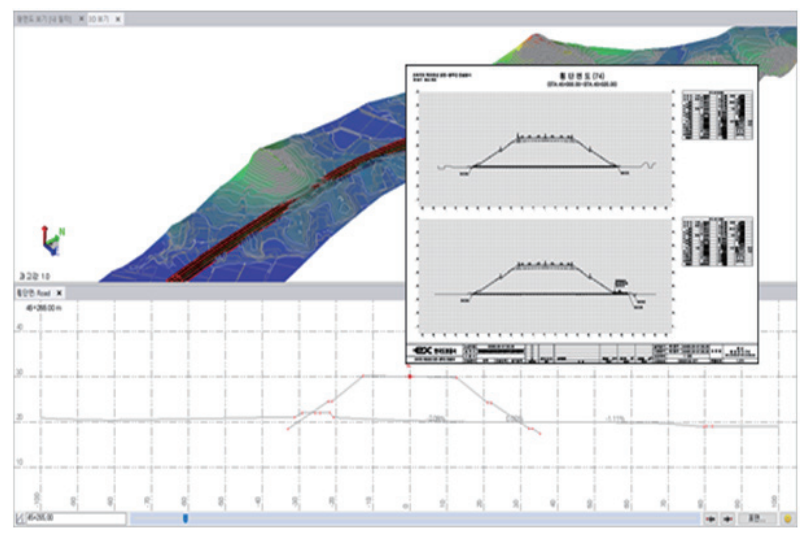

Fig. 13. (Color online) Design check.

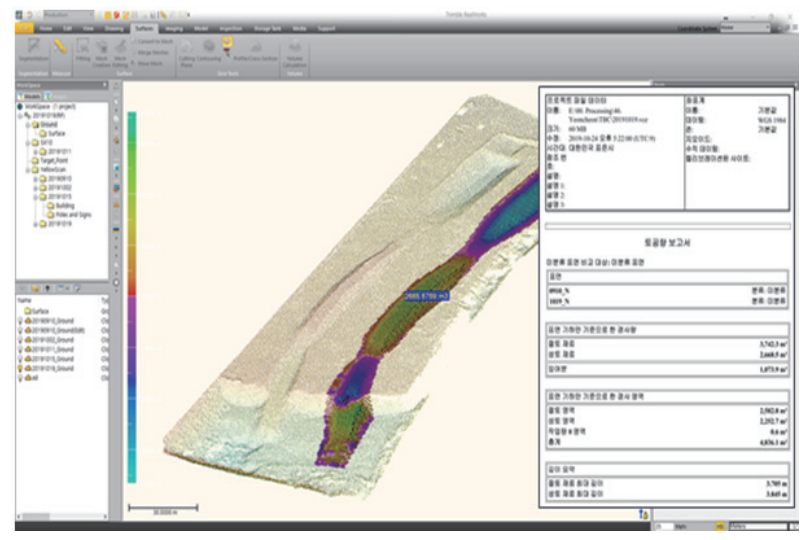

Fig. 14. (Color online) Calculation of amount of earthwork.

various sensors were installed on the construction equipment, such as hydraulic sensors and GNSS, and modems for communication were also installed. Figure 15 shows the construction equipment and sensors. 


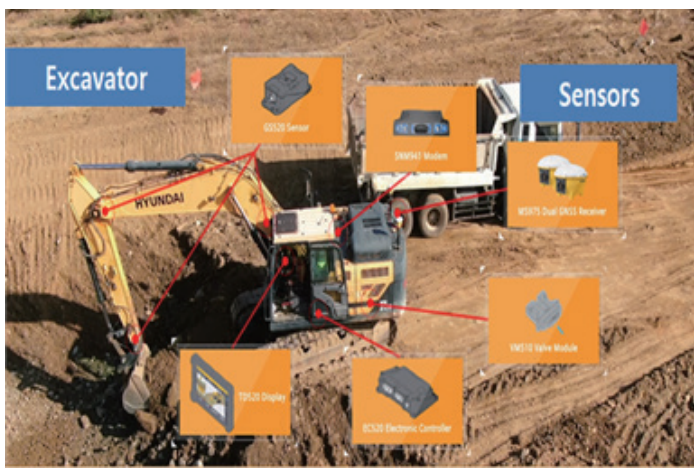

(a)

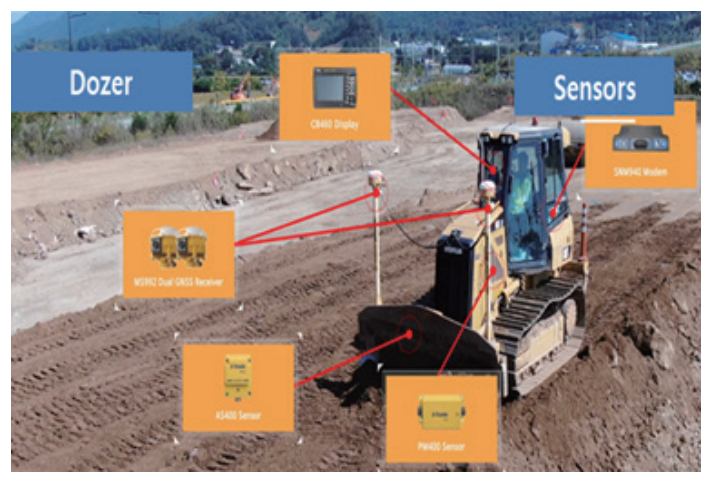

(b)

Fig. 15. (Color online) Construction equipment and sensors. (a) Excavator. (b) Dozer.

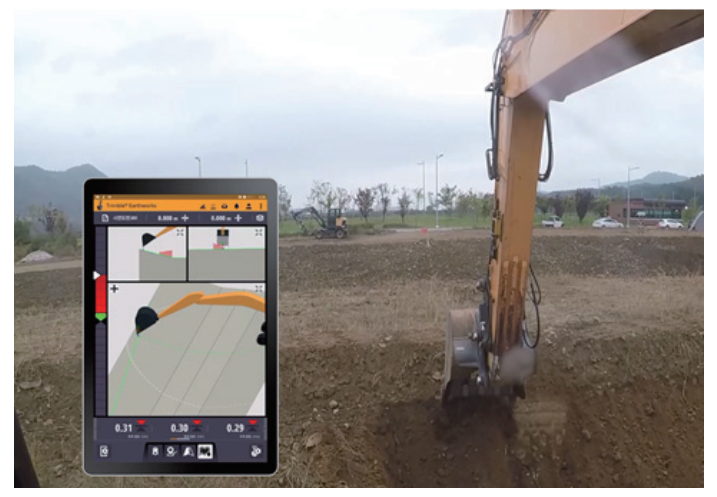

Fig. 16. (Color online) Work screen for automated construction.

In the traditional road construction method, it is necessary to continuously perform GNSS surveys during the work and compare and correct the design values. However, automated construction has the advantage of being able to know the design values and the condition of the site in real time using the sensors installed on the equipment. Figure 16 shows the work screen for automated construction.

The traditional and automated construction methods were applied at the target site, and the data obtained using static LiDAR and UAV LiDAR were acquired at stages corresponding to 20, 80 , and $100 \%$ of the construction being completed. Figure 17 shows geospatial information of the study area for each stage of construction.

A method of visualizing the process in real time at the construction site was also tested. This method uses augmented reality (AR), a GNSS receiver, and a smartphone, and can be used to manage construction in the field (Fig. 18). This method has the advantage of being able to check the process in real time at the construction site by comparing it with the design.

The LiDAR data acquired during construction work can be used for monitoring and checking construction. In addition, if a network is established, it will greatly help in managing construction in real time by using the data from the sensors attached to the equipment and 3D-built design data. Through an experiment on automated construction, an analysis was 


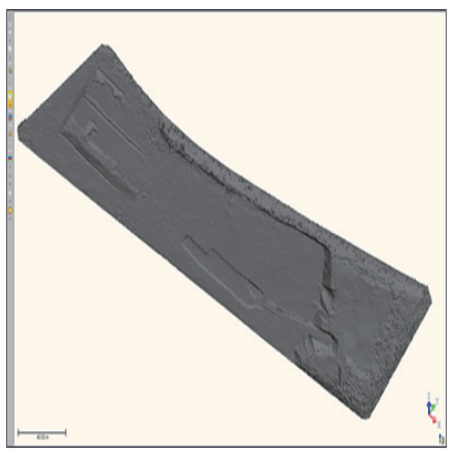

(a)

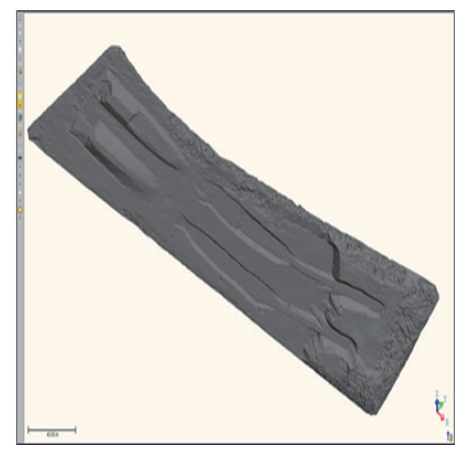

(b)

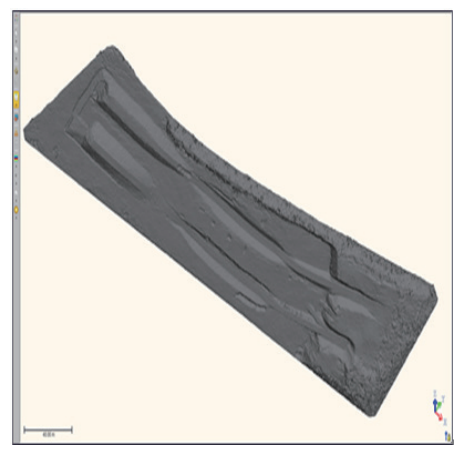

(c)

Fig. 17. (Color online) Geospatial information of the study area for each stage of construction: (a) 20, (b) 80, and (c) $100 \%$.
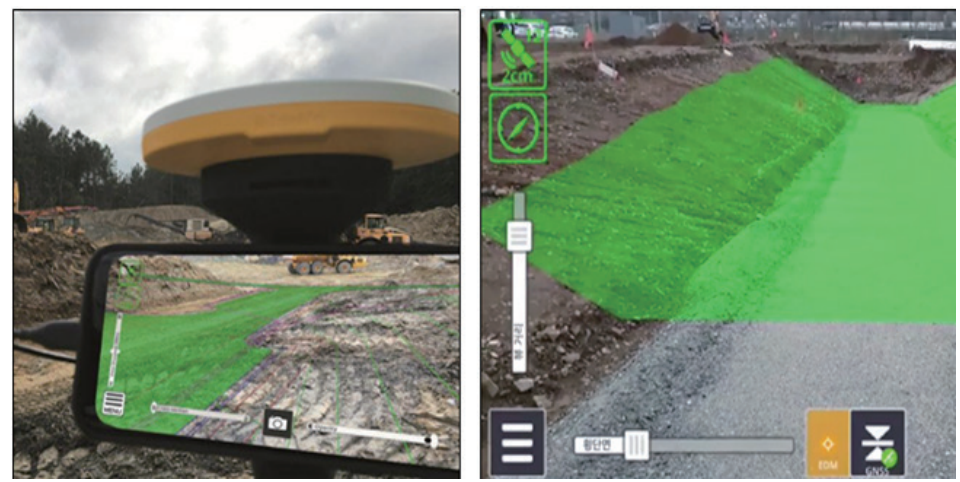

Fig. 18. (Color online) Construction management using AR.

conducted to evaluate the improvement in productivity compared with the traditional construction methods. Tables 2 and 3 show the results of the comparison between traditional construction and automated construction.

Table 2

Comparison of workload per minute $\left(\mathrm{m}^{3} / \mathrm{min}\right)$.

\begin{tabular}{lcccc}
\hline Method & Excavator & Dozer & Grader & Compactor \\
\hline Traditional construction & 1.70 & 1.36 & 0.41 & 6.32 \\
Automated construction & 2.41 & 2.22 & 0.97 & 8.42 \\
\hline
\end{tabular}

Table 3

Comparison of total working time (min).

\begin{tabular}{lccc}
\hline Item & Traditional construction & Automated construction & Reduction in working time \\
\hline Excavator & 981 & 660 & 321 \\
Dozer & 1413 & 1202 & 211 \\
Grader & 349 & 147 & 202 \\
Compactor & 303 & 242 & 61 \\
\hline Sum & & & 795 \\
\hline
\end{tabular}


Construction automation reduced the working time by about $13 \mathrm{~h}$ compared with the conventional method. Assuming $8 \mathrm{~h}$ of work per day, the number of work days was reduced by 1.6 days. Considering that the section of the road in the experiment was only about $260 \mathrm{~m}$, productivity will be considerably improved if construction automation is applied to an entire road construction site. In the future, construction automation using 3D geospatial information technology will contribute to improving productivity not only for roads, but also at many other construction sites such as tunnels.

\section{Conclusion}

In this study, an experiment on using 3D geospatial information technology in road construction was performed. The conclusions were as follows.

1. GNSS, static LiDAR, and UAV LiDAR were used to effectively build 3D geospatial information of the study area, and 3D designs were generated using the acquired data.

2. The accuracy of data constructed through static LiDAR and UAV LiDAR was found to be within $0.025 \mathrm{~m}$ in the $X, Y$, and $Z$ directions. Since the study area is not large, the accuracy of LiDAR will need to be verified through additional research.

3. A 3D design reflecting the actual terrain was created, and various sensors were installed on the construction equipment to conduct experiments on construction automation. Construction automation has the advantage of being able to know the design values and the condition of the site in real time using the sensors installed on the equipment.

4. The productivity of construction automation was evaluated by comparing the results of traditional and automated construction processes. In addition, a method using geospatial information and AR can visualize the process in the field, contributing to effective construction management.

5. In the future, construction automation using 3D geospatial information technology will contribute to improving productivity not only for roads, but also at many other construction sites such as tunnels.

\section{Acknowledgments}

This research was supported by the Basic Science Research Program through the National Research Foundation of Korea (NRF) funded by the Ministry of Science and ICT (No. NRF2021R1F1A1061677).

\section{References}

1 M. S. Kim and Y. B. Choi: J. Korea Acad.-Ind. Coop. Soc. 20 (2019) 85. https://doi.org/10.5762/ KAIS.2019.20.1.85

2 S. J. Kim, B. S. Kim, T. H. Kim, and N. G. Kim: J. Korea Acad.-Ind. Coop. Soc. 20 (2019) 208. https://doi. org/10.5762/KAIS.2019.20.11.208

3 J. W. Baik: Ind. Promot. Res. 5 (2020) 1. https://doi.org/10.21186/IPR.2020.5.4.001

4 D. H. Lee and J. W. Park: The J. Korea Con. Ass. 18 (2018) 303. https://doi.org/10.5392/JKCA.2018.18.06.303

5 D. H. Im, H. C. Yun, S. K. Kim, and J. W. Seo: J. Korean Soc. Civil Eng. 39 (2019) 893. https://doi.org/10.12652/ $\underline{\text { Ksce.2019.39.6.0893 }}$ 
6 D. S. Lee and G. H. Kim: J. Korea Inst. Build. Con. 20 (2020) 191. https://doi.org/10.5345/JKIBC.2020.20.2.191

7 J. S. Lee: J. Korea Ins. Inf. Com. Eng. 25 (2021) 1670.

8 H. J. Jung, J. Y. Oh, B. K. Kim, and I. Y. Ji: J. Korea Acad.-Ind. Coop. Soc. 19 (2018) 370. https://doi. org/10.5762/KAIS.2018.19.2.370

9 G. R. Park: J. Korea Con. Soc. 11 (2020) 61. https://doi.org/10.15207/JKCS.2020.11.3.061

10 S. W. Noh, Y. H. Song, and J. M. Choi: J. Korea Acad.-Ind. Coop. Soc. 19 (2018) 551. https://doi.org/10.5762/ KAIS.2018.19.4.551

11 S. C. Hong, T. I. Chung, J. M. Park, and H. S. Shin: J. Korea Acad.-Ind. Coop. Soc. 20 (2019) 630. https://doi. org/10.5762/KAIS.2019.20.7.630

12 B. G. Lee: J. Korean Soc. Sur. Geo. Pho. Car. 36 (2018) 335. https://doi.org/10.7848/ksgpc.2018.36.5.335

13 H. D. Seo and E. M. Kim: J. Korean Soc. Sur. Geo. Pho. Car. 37 (2019) 335. https://doi.org/10.7848/ ksgpc.2019.37.6.405

14 Y. J. Jang, J. W. Lee, and J. H. Oh: J. Korean Soc. Sur. Geo. Pho. Car. 37 (2019) 315. https://doi.org/10.7848/ ksgpc.2019.37.5.315

15 Trimble Inc., R10: https://www.trimble.com/ (accessed March 2020).

16 Trimble Inc., SX10: https://www.trimble.com/ (accessed March 2020).

17 YellowScan, SurveyorUltra: https://www.yellowscan-lidar.com/ (accessed March 2020). 